\title{
KAJIAN USAHATANI SAYURAN BANTARAN SUNGAI BARABAI PASCA BANJIR DI KABUPATEN HULU SUNGAI TENGAH
}

\author{
(Vegetables Farming Study of Barabai Riverbank Post The Flood \\ In Hulu Sungai tengah District)
}

Fitri Mahyudi dan Husinsyah

Program Studi Agribisnis Fakultas Pertanian

Universitas Achmad Yani Banjarmasin"

Penulis Koresponden: fitri.mahyudi@yahoo.co.id

Article Submitted : 19-06-2021

Article Accepted : 15-09-2021

\begin{abstract}
This Research aim to know technically about Vegetables Farming Study of Barabai Riverbank Post The Flood In Hulu Sungai tengah District and to know about cost, acceptance, revenue and vegetables farming Feasibility. Pursuant to result of seen from technical management vegetables farming still relative modestly, this seen from farm processing until the conservancy. Tomato Net Profit obtained from 32 vegetables farmer in Alat village and 27 vegetables farmer in Datar Ajab village responder Barabai Riverbank Post The Flood In Hulu Sungai tengah District with wide mean equal to Rp. 5.594.002,34/farmer and Chili Net Profit with wide mean equal to Rp. 6.919.998,88.002,34/farmer. RCR Value Tomato farming 1.15 and RCR Value Chili farming 1.20 competent so that to be feasible ( $R C R>1$ ).
\end{abstract}

Keywords: Farming, Tomato, Chili, Cost, Revenue, Feasibility, RCR

\section{PENDAHULUAN}

Banjir dahsyat memporak porandakan Provinsi Kalimantan Selatan tak terkecuali di Kabupaten Hulu Sungai Tengah (HST), banjir yang melanda Kabupaten Hulu Sungai Tengah pada bulan Januari 2021 menyebabkan hancurnya infrastruktur, korban jiwa, lahan pertanian dan hancurnya bantaran sungai yang diperkirakan akibat penurunan luas hutan alam di Daerah Aliran Sungai (DAS).

Daerah Aliran Sungai (DAS) Sungai Barabai berada di Kabupaten Hulu Sungai Tengah yang meliputi 11 (sebelas) kecamatan, yaitu Kecamatan Haruyan, Batu Benawa, Hantakan, Batang Alai Selatan, Batang Alai Timur, Barabai, Labuan Amas Selatan, Labuan Amas Utara, Pandawan, Batang Alai Utara dan Limpasu. Peningkatan perekonomian dan bidang lainnya di Kabupaten Hulu Sungai Tengah memacu pertumbuhan penduduk sehingga seiring dengan bertambahnya jumlah penduduk di Kabupaten Hulu Sungai Tengah sudah tentu kebutuhan akan air baku untuk masyarakat semakin meningkat. Kebutuhan akan air baku adalah kebutuhan pokok bagi masyarakat sehingga pemerintah menyediakan kebutuhan akan air baku guna mendukung kesejahteraan masyarakat Kabupaten Hulu Sungai Tengah. Pemerintah Kab. Hulu Sungai Tengah juga telah melaksanakan upaya peningkatan produksi pangan melalui kegiatan intensifikasi dan ekstensifikasi daerah irigasi di Kab. Hulu Sungai Tengah dan bencana banjir juga sering terjadi sehingga perlu dilakukan usaha berupa pembangunan bendungan dengan diawali dengan kegiatan studi kelayakan ini. Bencana Banjir tersebut telah 
menjadi permasalahan bagi petani sayuran di bantaran sungai barabai untuk kembali membudidayakan sayuran di lahan bekas banjir tersebut

Sayuran jenis hortikultura sangat penting bagi kehidupan sebuah daerah terutama perdesaan. Dalam yaitu sebagai sumber gizi dan mampu menghasilakn pendapatan bagi warga dan juga devisa bagi negara (Patricia, 2001). Pertanian organik adalah teknik budidaya pertanian yang mengandalkan bahan-bahan alami tanpa menggunakan bahan-bahan kimia sintetis. Tujuan utama pertanian organik adalah menyediakan produk-produk pertanian, terutama bahan pangan yang aman bagi kesehatan produsen dan konsumennya serta tidak merusak lingkungan (Raja Milyaniza, 2017).

Untuk komoditi yang banyak diusahakan masyarakat di Kecamatan Hantakan adalah tanaman tomat dan cabai besar. Petani di Kecamatan Hantakan tergolong petani tradisional dan masih menggunakan alat-alat yang sederhana, dan petani belum bisa memperhitungkan mengenai biaya yang dikeluarkan, sehingga petani tidak dapat menaikkan pendapatan keluarga.

Permasalahan yang dihadapi oleh petani di bantaran sungai di kecamatan Hantakan yaitu datangnya bencana banjir yang menghancurkan lahan mereka, kurangnya modal, timbulnya berbagai hama dan penyakit, harga jual yang tidak tetap. Masalah diatas inilah peneliti ingin melihat dan mengamati keberadaan serta kegiatan usahatani sayuran bantaran sungai ini. Baik berupa

pengeluaran/cost, revenue, pendapatan dan keuntungan petani serta kelayakan usahatani tersebut pasca musibah bencana banjir.

\section{METODE PENELITIAN}

Penelitian ini dilaksanakan pada bulan April - Juni 2021 di Kecamatan Hantakan yaitu Desa Alat dan Desa Datar Ajab. Penentuan lokasi penelitian berdasarkan pertimbangan bahwa di

Desa Alat dan Desa Datar Ajab merupakan sentra produksi tomat dan cabai besar terbesar di Kecamatan Hantakan.

Penentuan responden petani sayuran di bantaran sungai hantakan yaitu teknik Simple Random Sampling dan penggunaan rumus teknik Slovin, yaitu 32 responden petani di bantaran sungai di Desa Alat dan 27 responden di Desa Datar Ajab (Syarifudin A. Kasim, 1995). Data yang dikumpulkan meliputi data primer dan data sekunder. Metode pengolahan dan analisis data menggunakan analisis deskriptif (Ria Setiana, Anwar dan Addinul Yakin, 2019).

Menurut Soekartawi, (2006), biaya total adalah akumulasi dari penambahan biaya tetap yang dikeluarkan petani sayuran bantaran sungai dengan biaya variable yang dikeluarkan.

TC usahatani sayuran bantaran sungai = TEC usahatani sayuran bantaran sungai + TIC usahatani sayuran bantaran sungai Keterangan

TC usahatani sayuran bantaran sungai = Biaya Total (Rp)

TEC usahatani sayuran bantaran sungai = Total Biaya Ekplisit UT Sayuran (Rp)

TIC usahatani sayuran bantaran sungai = Total Biaya Implisit UT sayuran (Rp)

Menurut Ronny (2010), penerimaan total usahatani sayuran bantaran sungai secara di jelaskan bahwa jumlah produk yang terjual dikalikan dengan harga sayuran tersebut. Secara matematis penerimaan total dapat dirumuskan sebagai berikut:

$$
\mathbf{T R}=\mathbf{P} \times \mathbf{Q}
$$

Keterangan :

TR usahatani sayuran bantaran sungai $=$ Penerimaan total UT sayuran $(\mathrm{Rp})$

$\mathrm{P}$ sayuran bantaran sungai $=$ Harga produk sayuran bantaran sungai (Rp)

$\mathrm{Q}$ sayuran bantaran sungai = Jumlah produk sayuran di bantaran sungai $(\mathrm{Kg})$ 
Menurut Syarifuddin A. Kasim (1995), rumus pendapatan adalah sebagai berikut:

I usahatani sayuran bantaran sungai = TR usahatani sayuran bantaran sungai TVC usahatani sayuran bantaran sungai Keterangan :

I usahatani sayuran bantaran sungai = Pendapatan Total (Rp)

TR usahatani sayuran bantaran sungai $=$ Penerimaan Total (Rp)

TVC usahatani sayuran bantaran sungai $=$ Biaya Variabel Total (Rp)

Adapun Kelayakan usahatani sayuran bantaran sungai secara ekonomis dapat dinilai dengan persamaan sebagai berikut (Kasmir dan Jakfar, 2008).

$$
\text { R/C Ratio }=\frac{\text { TR }}{\text { TC }}
$$

Keterangan :

TR usahatani sayuran bantaran sungai $=$ Penerimaan Total usahatani sayuran bantaran sungai $(\mathrm{Rp})$
TC usahatani sayuran bantaran sungai $=$ Biaya Total usahatani sayuran bantaran sungai (Rp)

$\mathrm{R} / \mathrm{C}$ Ratio > 1 : usaha dikatakan layak

$\mathrm{R} / \mathrm{C}$ Ratio $=1$ : usaha dikatakan berada di titik impas

R/C Ratio < 1 : saha dikatakan tidak layak (Rita Feny, Edy Marwan, 2017).

\section{HASIL DAN PEMBAHASAN}

Kecamatan Hantakan terletak pada Koordinat $20^{\circ} \mathrm{LS}$ dan pada $115^{\circ} \mathrm{BT}$. Secara geografis batas administratif Kecamatan Hantakan, yaitu:

Batas utara :Kecamatan Batang

Alai Timur

Batas selatan : Kabupaten Hulu

Sungai Selatan

Batas timur : Kabupaten Kotabaru

Batas barat : Kecamatan Batu Benawa dan Kecamatan Haruyan

Kecamatan Hantakan terdiri dari 12 desa, dengan luas wilayah administratif Kecamatan Hantakan seluas 191,98 km2.

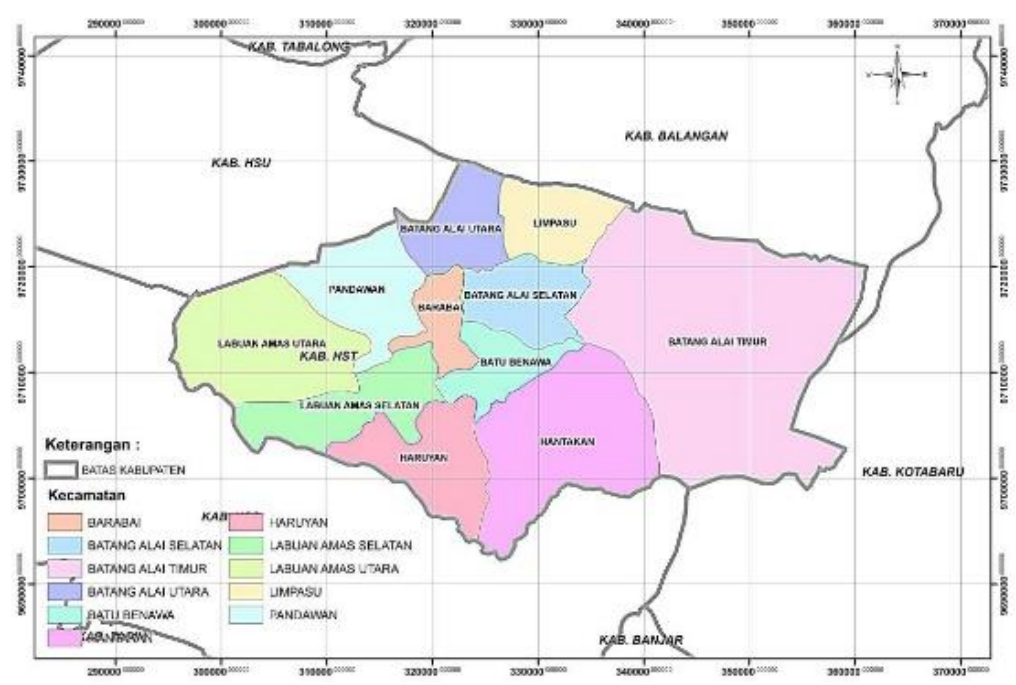

Gambar 1 Peta Kabupaten Hulu Sungai Tengah Provinsi Kalimantan Selatan

Pada Gambar 1 terlihat Lokasi Kabupaten Hulu Sungai Tengah yang memiliki luas wilayah $1.770,80 \mathrm{~km}^{2}$ yaitu 3,92 persen dari total luas wilayah Provinsi Kalimantan Selatan. Wilayah tersebut terbagi menjadi 11 kecamatan. Kecamatan
Batang Alai Timur merupakan kecamatan dengan luas wilayah terbesar $43,98 \%$ sedangkan kecamatan dengan luas wilayah terkecil adalah kecamatan Barabai yaitu 2,3\% dari total luas Kabupaten Hulu Sungai Tengah. 
Tabel 1. Kondisi Sosial Masyarakat di Kecamatan Hantakan, 2010 dan 2019

\begin{tabular}{lccc}
\hline Kelurahan/Desa & 2010 & 2019 & $\begin{array}{c}\text { Penduduk } \\
\text { per Tahun }(\%)\end{array}$ \\
\hline Datar Ajab & 370 & 409 & 1,26 \\
Alat & 1661 & 1838 & 1,27 \\
Hantakan & 1372 & 1518 & 1,27 \\
Hinas Kanan & 496 & 549 & 1,28 \\
\hline
\end{tabular}

Sumber : Kecamatan Hantakan Dalam Angka 2020

Wilayah Kabupaten Hulu Sungai Tengah yang tertinggi berada pada gugusan Pegunungan Meratus, yaitu Gunung Besar (Halau-halau) dengan ketinggian $1.892 \mathrm{~m}$ dpl, sekaligus sebagai titik tertinggi di Kalimantan Selatan. Sedangkan berdasarkan kelerengan didominasi kelas lereng agak curam/ sedang $(15-25 \%)$ seluas $34,70 \%$, landai/datar $(8-15 \%)$ seluas $27,41 \%$, sangat curam/sangat berat $(>45 \%)$ seluas $19,51 \%$, berat/curam $\quad(25-45 \%)$ seluas $15,80 \%$, dan sisanya datar sekali $(0-8 \%)$ seluas $2,59 \%$.

Desa Datar Ajab dan Desa Hinas Kanan merupakan dua dari 12 desa / kelurahan yang ada di Kecamatan Hantakan dengan jumlah penduduk dan persentase laju pertumbuhan penduduk seperti disajikan pada Tabel 1.

Dari Tabel 1 terlihat bahwa warga Desa Datar Ajab berjumlah 409 jiwa dengan laju pertumbuhan penduduk $1,26 \%$ dan warga Desa Hinas Kanan berjumlah 549 jiwa

Untuk bisa sampai ke lokasi penelitian dapat menggunakan roda transportasi motor (R2) atau jenis transportasi mobil (roda 4), dengan waktu tempuh dari Kota Banjarmasin \pm 3 jam, dengan melewati jalan provinsi. Adapun lokasi kegiatan studi kelayakan terdapat di Gambar 2 berikut.

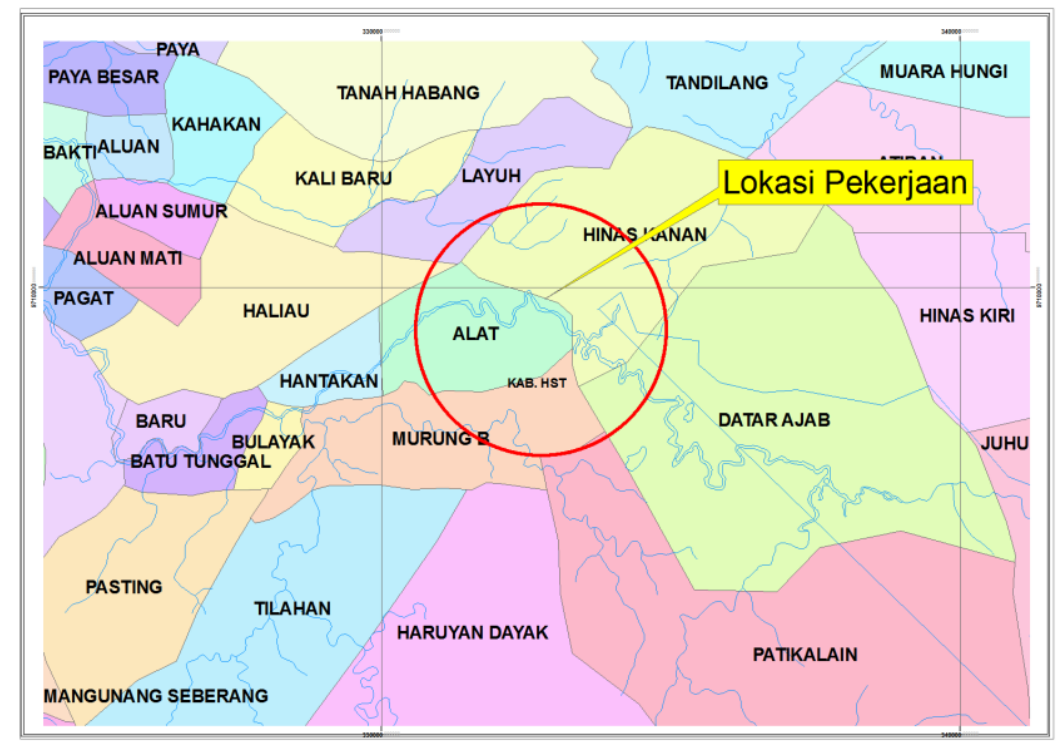

Gambar 2 Peta Lokasi Penelitian Sungai Barabai

Pada Gambar 2 terlihat lokasi penelitian adalah Desa Alat dan Desa Datar
Ajab yang berada di bantaran Sungai Barabai. Penduduk Desa Datar Ajab dan 
Desa Hinas Kanan tergolong masyarakat yang agamis dan mayoritas pemeluk agama Hindu-Kepercayaan. Kegiatan keagamaan menjadi ciri khas masyarakat dan mendapat akulturasi dari budaya islam dan adat dayak. Suku yang dominan Desa Datar Ajab dan Desa Hinas Kanan adalah suku dayak dan sedikit suku banjar

Adat istiadat yang berpengaruh besar di Desa Datar Ajab dan Desa Hinas Kanan tersebut adalah Adat Dayak. Namun dari semua adat istiadat yang berlaku di Desa Datar Ajab dan Desa Hinas Kanan semuanya sangat bernafas HinduKepercayaan seperti halnya dalam pergaulan, upacara perkawinan dan lain-lain. Adapun usaha-usaha dalam bidang pertanian yang terdapat di Desa Alat yang banyak diusahakan adalah Padi (Oryza sativa) Cabai besar (Capsicum annum L) dan Tomat (Solanum lycopersicum). Sedangkan tanaman seperti Ubi kayu (Manihot utilisima), tanaman Bayam ( Amaranthus sp), Semangka (Citrullus lanatus), terong (solanum melongena), labu (Cucurbita moscola), mentimun (Cucumis sativus) dan lain-lain juga diusahakan di Desa Alat dalam skala kecil.

Kebutuhan air bersih oleh penduduk digunakan untuk mandi, cuci dan air untuk kakus sebagian kecil dipenuhi dari sumber air dari ledeng warga dan sungai. Air untuk keperluan minum dan memasak diambil dari sumber yang sama yaitu ledeng, sumur gali, sisanya menggunakan air sungai . Dilihat dari kualitas fisik, sebagian besar penduduk menyatakan airnya cenderung cukup bersih terutama penduduk yang menggunakan air baik sumur gali maupun air sungai sehingga air dari sungai tersebut tidak perlu diolah dahulu. Sebagian besar penduduk menyatakan bahwa kuantitas air yang digunakan cukup sepanjang tahun yang berarti tidak kering saat musim kemarau ( $95 \%)$.

\section{Tanaman Tomat}

Pengadaan benih tomat dilakukan dengan cara membeli yang telah siap tanam. Mutu benih yang disiapkan harus memiliki kualitas yang utuh dan sehat sehingga dapat meningkatkan produksi, mutu benih yang dipilih tidak cacat atau luka, tidak menunjukkan adanya serangan hama atau penyakit (Wiryanta, 2002).

Tahapan tahapan dalam pengolahan tanaman tomat sebagai berikut:

a. Pembentukan bedengan dapat dibuat dengan ukuran lebar $1-1,2 \mathrm{~m}$, panjang disesuai dengan keadaan lahan dan tinggi bedengan $30 \mathrm{~cm}$.

b. Pengemburan tanah dicangkul dengan kedalaman $23-30 \mathrm{~cm}$.

c. Pemberian kapur pada tanah yang terlalu asam dan tidak sesuai dengan persyaratan

d. Pemupukan dasar dengan pupuk kandang dan diratakan di atas tanah bedengan.

\section{B iaya Eksplisit}

Biaya eksplisit adalah biaya keseluruhan biaya yang dikeluarkan dalam satu musim tanam. Biaya ini meliputi penyusutan alat, pajak lahan, TKLK, dan saprodi. Untuk lebih jelasnya dapat dilihat pada Tabel 2.

Dari Tabel 2 diketahui, penggunaan biaya tertingi dan terendah pada petani yaitu biaya tertinggi pada saprodi sebesar Rp. 21.885.136,00 (73,68 \%) sedangkan biaya penggunaan terandah pada pajak lahan yaitu sebesar Rp. 12.447 .33 (0,04\%). 
Tabel 2. Biaya Eksplisit Rata-rata yang dikeluatkan pada Usahatani Tomat di Kecamatan Hantakan.

\begin{tabular}{llrc}
\hline No & \multicolumn{1}{c}{ Uraian } & Biaya $(\mathrm{Rp})$ & Persentase $(\%)$ \\
\hline 1 & Penyusutan alat & $4.337 .261,33$ & 14,60 \\
2 & Pajak lahan & $12.447,33$ & 0,04 \\
3 & Saprodi & $21.885 .136,00$ & 73,68 \\
4 & TKLK & $3.470 .421,00$ & 11,68 \\
\hline & Jumlah & $29.705 .265,66$ & 100,00 \\
\hline
\end{tabular}

Sumber : Pengolahan Data Primer 2021

\section{B iaya Implisit}

Dari Tabel 3 diketahui, penggunaan biaya TKDK sebesar Rp. 6.214.409,33
$(86,78 \%)$ sedangkan biaya bunga modal yaitu sebesar Rp. 946.450,67 (13,22\%).

Tabel 3. Biaya Implisit Rata-rata yang dikeluarkan pada Usahatani Tomat di Kecamatan Hantakan.

\begin{tabular}{llcc}
\hline No & \multicolumn{1}{c}{ Uraian } & Biaya (Rp) & Persentasi (\%) \\
\hline 1 & TKDK & $6.214 .409,33$ & 86,78 \\
2 & Bunga Modal & $946.450,67$ & 13,22 \\
\hline & Jumlah & $7.160 .860,00$ & 100,00 \\
\hline
\end{tabular}

Sumber : Pengolahan Data Primer 2021

Biaya Total

Biaya total adalah hasil dari nilai tambahan biaya eksplisit dan biaya implisit dari penyelenggaraan usahatani tomat.

Tabel 4. Biaya Total Rata-rata yang dikeluarkan petani pada Usahatani Tomat di Kecamatan Hantakan.

\begin{tabular}{clcc}
\hline No & \multicolumn{1}{c}{ Uraian } & Biaya (Rp) & Persentasi (\%) \\
\hline 1 & Total Biaya Eksplisit & $29.705 .265,66$ & 80,58 \\
2 & Total Biaya Implisit & $7.160 .860,00$ & 19,42 \\
\hline \multicolumn{2}{l}{ Jumlah } & $36.866 .125,66$ & 100,00 \\
\hline
\end{tabular}

Sumber : Pengolahan Data Primer Tahun 2021

Tabel 4 menjelaskan yaitu biaya Total Biaya Eksplisit sebesar Rp. 29.705.265,66 (80,58\%) sedangkan Total Biaya Implisit yaitu sebesar Rp. 7.160.860,00 (19,42\%). Sehingga biaya total yang digunakan dalam usahatani tomat adalah rata-rata Rp. 36.866.125,66/petani.

Dari hasil wawancara dengan seluruh petani responden diperoleh total rata-rata produksinya adalah sebesar 13.268,79 $\mathrm{Kg} /$ petani dengan harga tomat Rp. 3.200/kg. Sehingga total penerimaan rata-rata adalah
Rp. 42.460.128/petani. Pendapatan petani sayuran di bantaran sungai hantakan adalah Rata-rata sebesar Rp. 12.754.862,34/petani dan . Keuntungan total yang diperoleh rata-rata sebesar $\mathrm{Rp}$. 5.594.002,34/petani.

\section{Kelayakan}

Untuk usahatani tomat didapat total penerimaan rata-rata adalah $\mathrm{Rp}$. 42.460.128/petani dan biaya total yang digunakan dalam usahatani tomat adalah rata-rata $\quad \mathrm{Rp} . \quad 36.866 .125,66 /$ petani. 
Sehingga didapat nilai RCR adalah 1.15. Nilai RCR usahatani tomat yang lebih besar dari 1 dapat disimpulkan usahatani tomat di Kecamatan Hantakan layak untuk dijalankan.

\section{Tanaman Cabai Besar}

Pemetikan perdana (panen pertama) dilakukan saat tanaman cabai (varietas unggul) berumur sekitar 80-85 hari setelah hari tanam pertama. Tanaman cabai besa (varietas unggul)r yang terawat baik akan dapat dipetik(dipanen) $20-25$ kali petik setiap 4 hari sekali (Cahyono, 2003). Jumlah biaya eksplisit yaitu sebesar Rp. 245.423.460 atau rata-rata sebesar $\mathrm{Rp}$. 24.542.346/petani. Untuk lebih jelasnya dapat dilihat pada Tabel 5 .

Tabel 5 . Rata-rata Biaya Eksplisit Yang Dikeluarkan Pada Usahatani Cabai Besar Kecamatan Hantakan

\begin{tabular}{llrc}
\hline No & Uraian & $\begin{array}{c}\text { Jumlah } \\
(\mathrm{Rp})\end{array}$ & Persentasi (\%) \\
& & $56.000,33$ & 0,21 \\
\hline 1. & Penyusunan alat & $8.556 .500,00$ & 32,58 \\
2. & TKLK & $10.650,00$ & 0,04 \\
3. & Pajak lahan & $17.641 .050,00$ & 67,17 \\
4. & Saprodi & $26.264 .200,33$ & 100,00 \\
\hline & Jumlah &
\end{tabular}

Sumber : Pengolahan Data Primer Tahun 2021

Biaya ekplisit rata-rata yang

dikeluarkan dalam penyelenggaraan

usahatani cabai besar rata-rata sebesar Rp. 26.264.200,33/petani.

Tabel 6. Biaya Implisit Rata-rata Yang Dikeluarkan Pada Usahatani cabai besar di Kecamatan Hantakan

\begin{tabular}{clcc}
\hline No. & \multicolumn{1}{c}{ Uraian } & Jumlah $(\mathrm{Rp})$. & Persentasi $(\%)$ \\
\hline 1. & TKDK & $7.558 .000,00$ & 90,62 \\
2. & Sewa Lahan & $37.500,00$ & 0,45 \\
3. & Bunga Modal & $744.500,79$ & 8,93 \\
\hline & Jumlah & $8.340 .000,79$ & 100,00
\end{tabular}

Sumber : Pengolahan Data Primer Tahun 2021

Biaya Total

Biaya total adalah hasil dari nilai tambahan biaya eksplisit dan biaya implisit dari penyelenggaraan usahatani tomat.

Tabel 7. Biaya Total Rata-rata yang dikeluarkan petani pada Usahatani Cabai Besar di Kecamatan Hantakan.

\begin{tabular}{clcc}
\hline No & \multicolumn{1}{c}{ Uraian } & Biaya $(\mathrm{Rp})$ & Persentasi $(\%)$ \\
\hline 1 & Total Biaya Eksplisit & $26.264 .200,33$ & 75,90 \\
2 & Total Biaya Implisit & $8.340 .000,79$ & 24,10 \\
\hline & Jumlah & $34.604 .201,12$ & 100,00 \\
\hline
\end{tabular}

Sumber : Pengolahan Data Primer Tahun 2021

Dari Tabel 7 diketahui, penggunaan biaya Total Biaya Eksplisit sebesar Rp.
26.264.200,33 (75,90\%) sedangkan Total Biaya Implisit yaitu sebesar Rp. 
8.340.000,79 (24,10\%). Sehingga biaya total yang digunakan dalam usahatani tomat adalah rata-rata Rp. 34.604.201,12/petani.

Besarnya penerimaan sebesar Rp. 41.524.200,00. Pendapatan sebesar Rp. 15.259.999.67 dan keuntungan sebesar Rp. Rp. 6.919.998,88/petani selama petani mengusahakan cabai besar di bantaran sungai hantakan.

\section{Kelayakan}

Untuk usahatani tomat didapat total penerimaan rata-rata adalah $\mathrm{Rp}$. 41.524.200,00/petani dan biaya total yang digunakan dalam usahatani tomat adalah rata-rata $R p$ 34.604.201,12/petani. Sehingga didapat nilai RCR adalah 1.20. Nilai RCR usahatani tomat yang lebih besar dari 1 dapat disimpulkan usahatani tomat di Kecamatan Hantakan layak untuk dijalankan.

Pada penelitian kelayakan usahatani tomat di Provinsi Sulawesi Tengah tepatnya di Kelurahan Boyaoge yang merupakan lingkup daerah Kecamatan Tatanga Kota Palu diketahui bahwa nilai pendapatan sebesar Rp. 17.483.225/ha dengan nilai RCR sebesar 1.76 dengan jumlah responden 35 orang petani tomat. Nilai RCR usahatani tomat di Kecamatan Hantakan Kota Banjarbaru lebih tinggi yaitu 1,78 (Saddam Fadli, 2014).

Pada penelitian kelayakan usahatani tomat di Provinsi Jawa Timur tepatnya di Kabupaten Jember diketahui bahwa nilai produksi sebesar Rp. 1.004.200 kg dengan rata-rata sebesar 16.736,67 kg/petani dari 60 orang responden sedangkan Produksi yang diperoleh dari usahatani tomat di Kecamatan Hantakan dari 15 petani responden adalah $352.236,45 \mathrm{~kg}$ dengan rata-rata sebesar 23.482,43 kg/petani (Bagus Rangga Sita, Syamsul Hadi, 2016). Pada penelitian kelayakan usahatani tomat di Desa Gading Kulon Kecamatan Dau Kabupaten Malang Provinsi Jawa Timur diketahui bahwa nilai pendapatan sebesar Rp. 82.822.883/ha dengan nilai RCR sebesar 1.74. Dengan nilai
$\mathrm{RCR}>1$ maka usahatani tomat di Kabupaten Malang yang teapatnya di wilayah Desa Gading Kulon yang merupakan lingkup wilayah Kecamatan Dau layak diusahakan. Nilai RCR usahatani tomat di Kecamatan Hantakan Kota Banjarbaru lebih tinggi yaitu 1,78 (Aloysius Rabha Gempa, Eri Yusnita, Said Masduki, 2017).

Pada penelitian kelayakan usahatani tomat diantara pertanaman kelapa di Provinsi Sulawesi Utara tepatnya di wilayah Kabupaten Sangihe diketahui bahwa nilai pendapatan sebesar Rp. 10.690.000/0.3 ha, dengan sistem semi intensif penerimaan sebesar 14.840.000/0.2 ha dengan nilai RCR sebesar 4.36. Dengan nilai RCR > 1 maka usahatani tomat di Kabupaten Sangihe Provinsi Sulawesi Utara layak diusahakan. Tingginya Nilai RCR usahatani tomat di Kabupaten Sangihe Provinsi Sulawesi Utara yaitu 4,36 dibanding Nilai RCR usahatani tomat di Kecamatan Hantakan Kota Banjarbaru 1 yaitu 1,78 disebabkan penggunaan sistem semi intensif yaitu penanaman tomat diantara pertanaman kelapa. Hal ini perlu di aplikasikan oleh petani tomat di Kecamatan Hantakan Kota Banjarbaru sebagai nilai kebaharuan dimana penggunaan sistem semi intensif yaitu penanaman tomat diantara pertanaman kelapa belum pernah di aplikasikan di lokasi penelitian (Jantje G. Kindangen, Payung Layuk, 2015).

Pada penelitian kelayakan usahatani tomat di Desa Gunung Intan Kecamatan Babulu Darat Kabupaten Penajam Paser U tara Provinsi Kalimantan Timur didapat dan ketahui bahwa nilai pendapatan sebesar Rp. 55.419.840/ha dengan nilai RCR sebesar 2.84. Dengan nilai RCR > 1 maka usahatani tomat di Desa Gunung Intan Kecamatan Babulu Darat layak diusahakan. Nilai RCR usahatani tomat di Kecamatan Hantakan Kota Banjarbaru lebih rendah yaitu 1,78 (Siti Bilkis, Muhammad Najib, Elis Siti Masitoh, 2014). 


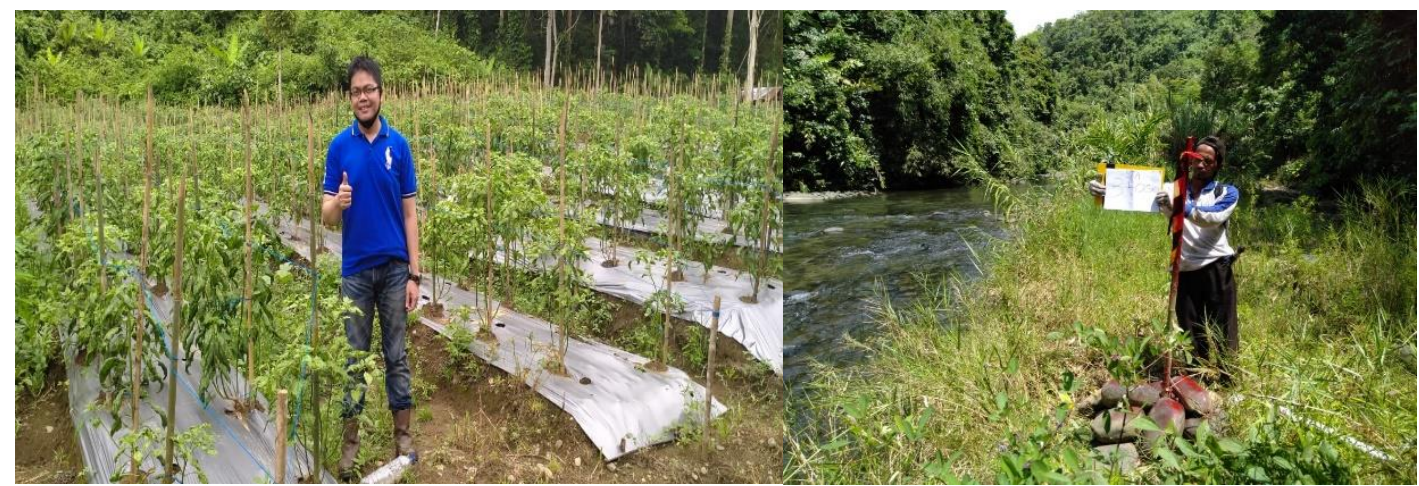

Gambar 3. Kondisi Eksisting Tanaman Sayuran Di Kecamatan Hantakan Dekat Aliran Sungai Barabai

\section{KESIMPULAN DAN SARAN}

\section{Kesimpulan}

Berdasarkan hasil penelitian terhadap usaha sayuran bantaran sungai hantakan, maka dapat ditarik kesimpulan adalah :

1. Dilihat dari teknis penyelenggaraan usahatani tomat dan cabai besar di Kecamatan hantakan pasca bencana banjir masyarakat secara teknis sudah kembali mengusahakan usatatani sayuran dan masih relatif sederhana, ini terlihat dari pengolahan lahan sampai pemeliharaan.

2. Pendapatan yang di peroleh petani Rata-rata sebesar Rp. 12.754.862,34/petani dan Keuntungan total yang diperoleh rata-rata sebesar Rp. 5.594.002,34/petani sedangkan untuk tanaman cabai besar besarnya penerimaan sebesar Rp. 41.524.200,00. Pendapatan sebesar Rp. 15.259.999.67 dan keuntungan sebesar Rp. Rp. 6.919.998,88/petani selama petani mengusahakan cabai besar

3. Nilai RCR usahatani tomat di Kecamatan Hantakan adalah 1.15 dan Nilai RCR usahatani Cabai Besar di Kecamatan Hantakan adalah 1.20 sehingga layak untuk diusahakan.

\section{Saran}

Untuk meningkatkan keberhasilan usaha tanaman sayuran di Kecamatan
Hantakan perlu dilakukan perbaikan infrastrukrur akibat bencana banjir seperti rusaknya akses jalan dan bangunan pasar hantakan serta peningkatan sumber daya manusia melalui peningkatan keterampilan petani, perbaikan penyelenggaraan usahatani, penyediaan sarana produksi dan penggunaannya yang sesuai anjuran, penggunaan tenaga kerja yang optimal melaui peningkatan kemampuan petani dalam penyelenggaraan usahatani tanaman sayuran yang berada di bantaran sungai Barabai.

\section{DAFTAR PUSTAKA}

Aloysius Rabha Gempa, Eri Yusnita, Said Masduki, 2017. Kelayakan Usahatani Tomat di Desa Gading Kulon Kecamatan D au Kabupaten Malang Provinsi Jawa Timur. Jurnal Fakultas Pertanian Vol.5 No.2 Universitas Tribhuwana Tunggadewi Jawa Timur

Bagus Rangga Sita, Syamsul Hadi. 2016. Produktivitas\&Faktor-

Faktor Yang

Berpengaruh Terhadap Produksi Usahatani Tomat

Di Kabupaten Jember .Jurnal JSEP Vol. 9 No.3 November 2016. 
Faperta Universitas Jember Jawa Timur.

Badan Pusat Statistik. 2020. Kecamatan Hantakan Dalam Angka

Cahyono, 1998. Tomat : Usahatani dan Penanganan Pasca Panen. Kanisius. Yogyakarta

Cahyono, B. 2003. "Bertanam Cabai Rawit. Yogyakarta: Penerbit Kanisius.p.28-32.

Jantje G. Kindangen, Payung Layuk, 2015. Kelayakan Usahatani Tomat Diantara Pertanaman Kelapa. Buletin Palma Vol.16 No.1. Balitka Sulawesi Utara

Kasmir dan Jakfar, 2008. Studi Kelayakan Agribisnis. Kencana Pr enada Media Group. Jakarta.

Patricia, 2001. Analisis Pendapatan Usahatani Tomat. Skripsi Fakultas Pertanian UNSRAT Manado.

Rita Feny, Edi Marwan. 2017. Analisis Biaya dan Pendapatan usahatani Sayuran di Kecamatan Ratu Agung Kota Bengkulu. Jurnal Agripita Vol.1 No.2 Tahun 2017. Fakultas Pertanian Universitas Sriwijaya. Palembang

Raja Milyaniza, 2017. Karakteristik dan Tingkat Kelayakan Usahatani Sayuran Organik-Anorganik. Jurnal Agrilan Vol. 5 No. 2 Tahun 2017. Fakultas Pertanian Universitas Pattimura. Ambon.
Ronny, 2010. Pendapatan Usahatai Campuran. Seminar hasil Penelitian Fakultas Pertaniaan UNSRAT Manado.

Ria Setiana, Anwar dan Addinul Yakin, 2019. Analisis Kelayakan Usahatani Sayuran Hidrofonik di Kota Mataram. Jurnal Agrimansion Vol.20 No.3 Tahun 2019. Fakultas Pertanian Universitas Mataram.

Saddam

Fadli, 2014.

Kelayakan Usahatani Tomat di Kelurahan Boyaoge Kecamatan Tatanga Kota Palu Pr ovinsi Sulawesi Tengah. Jurnal Agroland Vol.21 No.1. Fakultas Pertanian Universitas Tadulako Sulawesi Tengah.

Siti Bilkis, Muhammad Najib, Elis Siti Masitoh. 2014. Analisis Usahatani\&Pemasaran To mat Di Desa Gunung Intan Keca matan Babulu Darat Kab. Penajam Paser Utara Provinsi Kalimantan Timur. Jurnal Dinamika Pertanian Vol.29 No. 2 Agustus 2014. Universitas Mulawarman Samarinda.

Soekartawi, 2006. Analisis Usahatani. Universitas Indonesia, Jakarta.

Syarifuddin A.Kasim 1995.Pengantar Ekon omi Produksi Pertanian Universitas Lambung Mangkurat Banjarbaru.

Wiryanta, 2002. Bertanam Tomat, PT Agromedia Pustaka, Jakarta. 